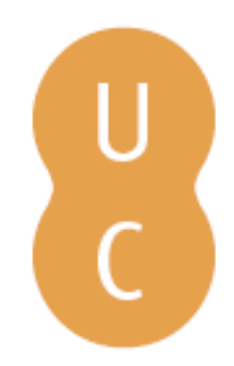

\title{
pommalina
}

\section{Avaliação e acompanhamento de projetos de I\&D numa empresa de telecomunicações}

Autor(es): $\quad$ Fialho, Joana; Godinho, Pedro; Costa, João Paulo; Afonso, Ricardo

Publicado por: Imprensa da Universidade de Coimbra

URL

persistente: URI:http://hdl.handle.net/10316.2/35943

DOI: $\quad$ DOI:http://dx.doi.org/10.14195/978-989-26-0738-2_21

Accessed : $\quad$ 26-Apr-2023 15:34:31

A navegação consulta e descarregamento dos títulos inseridos nas Bibliotecas Digitais UC Digitalis, UC Pombalina e UC Impactum, pressupõem a aceitação plena e sem reservas dos Termos e Condições de Uso destas Bibliotecas Digitais, disponíveis em https://digitalis.uc.pt/pt-pt/termos.

Conforme exposto nos referidos Termos e Condições de Uso, o descarregamento de títulos de acesso restrito requer uma licença válida de autorização devendo o utilizador aceder ao(s) documento(s) a partir de um endereço de IP da instituição detentora da supramencionada licença.

Ao utilizador é apenas permitido o descarregamento para uso pessoal, pelo que o emprego do(s) título(s) descarregado(s) para outro fim, designadamente comercial, carece de autorização do respetivo autor ou editor da obra.

Na medida em que todas as obras da UC Digitalis se encontram protegidas pelo Código do Direito de Autor e Direitos Conexos e demais legislação aplicável, toda a cópia, parcial ou total, deste documento, nos casos em que é legalmente admitida, deverá conter ou fazer-se acompanhar por este aviso.

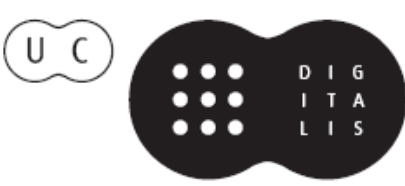




\section{INVESTIGAÇÃO OPERACIONAL EM AÇÃO \\ CASOS DE APLICAÇÃO}

RUI CARVALHO OLIVEIRA JOSÉ SOEIRO FERREIRA (EDITORES)

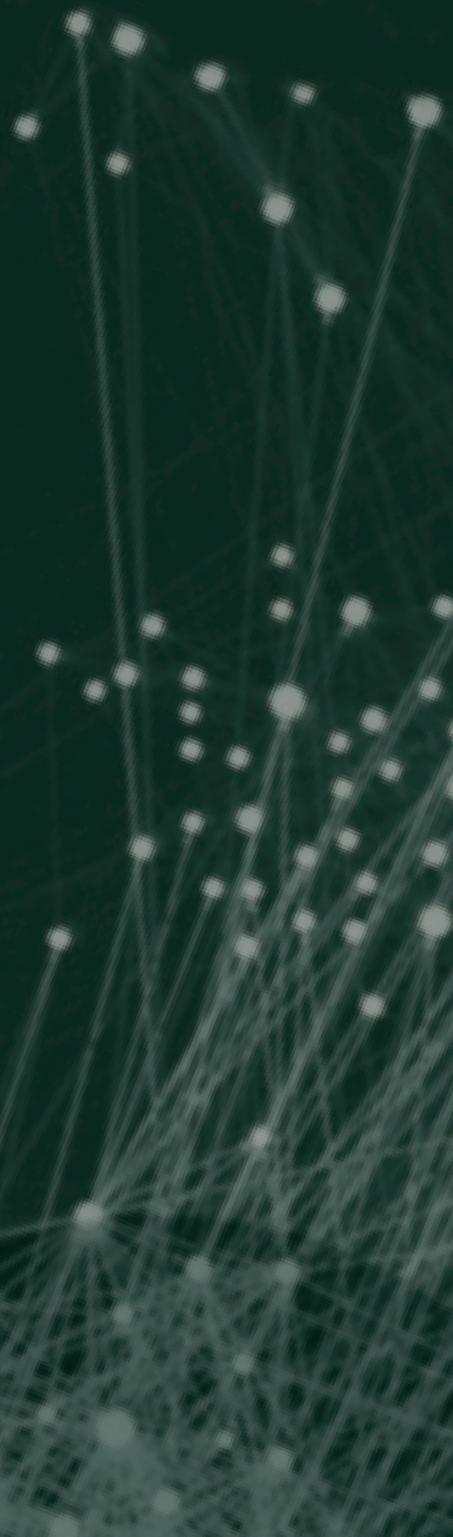




\title{
CASO 21
}

\section{AVALIAÇÃO E ACOMPANHAMENTO DE PROJETOS DE I\&D NUMA EMPRESA DE TELECOMUNICAÇÕES}

\author{
Joana Fialho \\ Área Científica de Matemática, Escola Superior de Tecnologia e Gestão de Viseu \\ Instituto de Engenharia de Sistemas e Computadores de Coimbra, INESC-C \\ jfialho@estv.ipv.pt \\ Pedro Godinho \\ Faculdade de Economia da Universidade de Coimbra \\ Grupo de Estudos Monetários e Financeiros, GEMF \\ pgodinho@fe.uc.pt \\ João Paulo Costa \\ Faculdade de Economia da Universidade de Coimbra \\ Instituto de Engenharia de Sistemas e Computadores de Coimbra, INESC-C, \\ jpaulo@fe.uc.pt \\ Ricardo Afonso \\ PT Inovação \\ ricardo@ptinovacao.pt
}




\section{RESUMO}

Neste capítulo, apresenta-se uma solução para a avaliação e seleção de projetos de Investigação e Desenvolvimento (I\&D) de uma empresa de telecomunicações (a PT Inovação), bem como o processo que a ela conduziu. A empresa dedica-se, por excelência, à inovação, investigação e desenvolvimento, pelo que uma correta alocação de recursos, baseada num modelo de avaliação das diferentes propostas com que a empresa se depara, é fundamental para que possa prosperar. No entanto, a avaliação deste tipo de projetos apresenta dificuldades específicas de índole diversa, e deve também ser devidamente enquadrada na política da empresa, pelo que se entendeu ser desejável definir uma solução de raiz, em vez de se optar por modelos predefinidos. A solução resulta de um processo iterativo que envolveu, por um lado, um conjunto de investigadores das áreas das finanças e investigação operacional e, por outro, vários elementos da empresa. A solução tem por base a avaliação comparativa das propostas com que a empresa se depara, e parte daí para a alocação de recursos entre os projetos selecionados. Os recursos mais importantes desta empresa são as pessoas, e a solução definida permite orientar os decisores relativamente à alocação das pessoas aos projetos.

\section{PALAVRAS-CHAVE}

Análise de Decisão Multicritério, Avaliação de projetos de I\&D, AHP 


\section{Introdução}

Os projetos de Inovação, Investigação e Desenvolvimento promovem o crescimento e o sucesso de uma empresa. É, pois, fundamental avaliar corretamente estes projetos para que a empresa possa estabelecer quais os que deve realizar e qual a quantidade de recursos a utilizar. Para avaliar projetos de investigação e desenvolvimento (I\&D), são necessárias ferramentas que tenham em conta o valor do projeto resultante da flexibilidade operacional que lhe é intrínseca, e a totalidade das fontes de incerteza a que pode estar sujeito. A avaliação depende da informação disponibilizada e, quando não existe informação quantitativa rigorosa, pode recorrer-se a fatores qualitativos, muitas vezes fornecidos por especialistas e gestores (Carlsson e Outros, 2007). A avaliação de projetos de I\&D depende, também, da informação que se vai obtendo ao longo do tempo de vida do projeto. Quando a informação é quantitativa, de natureza económica e rigorosa, podem aplicar-se métodos económicos, tais como a teoria das opções reais ou outros mecanismos que fornecem resultados mais rigorosos, já que existe informação financeira suficiente para tal. No caso da informação disponível ser qualitativa ou inferida a partir de fatores qualitativos, é necessário aplicar outro tipo de métodos que consiga explorar e avaliar os projetos, partindo desse tipo de informação. Pode também acontecer que a avaliação dos projetos seja feita recorrendo, simultaneamente, a fatores qualitativos e quantitativos.

Neste capítulo, pretende-se apresentar uma abordagem de avaliação de projetos de I\&D para uma empresa de telecomunicações - a PT Inovação. Os projetos de I\&D desta empresa apresentam características específicas, de índole diversa, que devem ser devidamente enquadradas numa abordagem de avaliação, pelo que se entendeu ser desejável definir, de raiz, esta abordagem em vez de se optar por outras já desenvolvidas. A abordagem resultou, assim, de um processo iterativo, que envolveu investigadores das áreas financeira e de investigação operacional, bem como elementos da própria empresa. A solução encontrada propõe a comparação dos diversos projetos disponíveis e, posteriormente, a partir dos resultados obtidos, apoia a alocação dos recursos aos projetos a empreender. Note-se que os recursos mais importantes desta empresa são pessoas com diferentes tipos e níveis de especialidade. A solução 
preconizada ajuda, portanto, os decisores a definirem a alocação das pessoas aos projetos.

A abordagem desenvolvida foi inspirada no processo desenvolvido para a British Aerospace Military Aircraft and Aerostrucutres, apresentado em Farrukh e Outros (2000). Tal como nesse processo, as reuniões com elementos da PT Inovação foram frequentes e fundamentais. Estas reuniões serviram, entre outros, para identificar o tipo de informação existente na empresa, bem como o tipo de informação que é razoável solicitar, a curto prazo, aos responsáveis pelas ações e pelos clusters (unidades orgânicas da empresa definidas na secção 2). Esta informação é essencial para a construção do modelo de avaliação. As reuniões serviram ainda para definir que se deveriam usar critérios gerais e subcritérios mais específicos, e para definir estes, bem como os parâmetros que devem integrar a sua avaliação.

No processo de avaliação, foi utilizada uma estrutura hierárquica baseada no processo analítico hierárquico (AHP) (Saaty, 1980). O método AHP é muito utilizado, inclusivamente na avaliação de projetos de I\&D. Por exemplo, Shin e Outros (2007) aplicam este método para avaliar projetos nucleares de I\&D na Coreia. Poh e Outros (2001) também utilizam o método AHP para comparar métodos de avaliação de projetos de I\&D.

No entanto, na abordagem apresentada, alguns aspetos do AHP foram modificados, de forma a poder ultrapassar algumas dificuldades, tais como o elevado número de comparações e a integração de critérios quantitativos e qualitativos. Existem outras dificuldades relacionadas com o AHP, como a alteração da ordem das alternativas, a escolha e utilização das escalas ou a escolha da forma como se deriva o vetor das prioridades. A alteração da ordem das alternativas, quando se introduz ou remove uma alternativa, é um problema do AHP que está muito debatido na literatura. Existem autores que criticam este fenómeno (Dyer, 1990a, 1990b; Holder, 1990, 1991; Stam e Silva, 2003) e outros que o legitimam (Harker e Vargas, 1987, 1990; Saaty, 1986, 1990, 1991, 1994a, 2006). Saaty (1997) defende que, usualmente, a ordem das alternativas é mantida se as alternativas são comparadas entre si, mas relativamente a um padrão ideal. Caso as alternativas sejam comparadas entre si, diretamente, sem nenhum padrão ideal definido, a alteração da ordem pode 
acontecer. Quando não há padrão ideal, preservar a ordem das alternativas, quando se modificam os critérios ou alternativas, mas não os julgamentos, é muito difícil. É da responsabilidade do agente de decisão saber se se deve ou não manter a ordem, quando se alteram critérios e/ou alternativas. Saaty (1994a, 1997) afirma que a alteração da ordem não é um problema, desde que o método AHP seja corretamente aplicado. No caso específico da abordagem aqui apresentada, os autores consideraram que a alteração da ordem das alternativas não seria, em geral, um problema grave. Apesar desta opinião dos autores, foi tido em conta que a possibilidade de ocorrer uma alteração da ordem podia causar desconforto nalguns utilizadores. Assim, foi definida uma forma de utilização da solução em que esta alteração não ocorre. Esta forma de utilização consiste na avaliação individual de cada alternativa em relação a um conjunto de alternativas padrão ou, usando a terminologia associada à abordagem, alternativas "de referência". Se os avaliadores optarem por esta forma de utilização da solução, então o aparecimento de uma nova alternativa nunca poderá causar a alteração da ordem das restantes, uma vez que o processo de avaliação de cada alternativa é independente das restantes (com exceção da normalização final das avaliações).

Apesar da existência de alguns problemas associados à utilização do método AHP, este consegue atingir o compromisso entre a usabilidade e uma boa modelação (Ishizaka e Labib, 2011). Na prática, este método é bastante utilizado na tomada de decisões, já que a sua estrutura hierárquica é simples de utilizar e bastante intuitiva. A utilização deste método permite a avaliação verbal e a análise de coerência dessa avaliação. Este é, também, um método que, facilmente, se integra num software ou numa folha de cálculo. Em relação à escolha da escala, manteve-se a escala proposta por Saaty, mas com a possibilidade de utilizar outros valores que não estejam contemplados nessa escala. A escala de Saaty serve de suporte ao decisor, de forma a existir um significado verbal para os valores, mas qualquer valor real positivo pode ser utilizado para comparar duas alternativas. Para a derivação do vetor das prioridades, utilizou-se o vetor próprio normalizado (com o modo distributivo) associado ao valor próprio máximo. 
A estrutura deste capítulo é a seguinte: na secção 2, é feito um enquadramento da abordagem de avaliação no seio da empresa; na secção 3, é descrita a estrutura e a parte técnica da solução proposta para a avaliação; na secção 4, o processo de utilização da abordagem de avaliação é apresentado; na secção 5, é dado um exemplo simples de aplicação; na secção 6, o impacto desta abordagem de avaliação na empresa é analisado e a secção 7 conclui.

\section{Enquadramento da abordagem de avaliação na empresa}

Numa fase preliminar, foi necessário compreender a estrutura da empresa na área da inovação, investigação e desenvolvimento. A apreensão desta estrutura, que em seguida se relata de forma sintética, ocorreu com o auxílio de elementos da empresa.

A empresa comporta dois grandes setores: serviços e projetos. Existem serviços de engenharia, de testes e consultoria, de formação e de divulgação da inovação. Os projetos podem incluir estudos e investigação aplicada, para aquisição de conhecimento, e desenvolvimento de sistemas e serviços integrados de soluções de telecomunicações.

Os serviços e projetos dividem-se em grandes grupos com características próprias, aproximadamente definidos por áreas de conhecimento e denominados clusters. Cada cluster é, por sua vez, composto por várias ações. Uma ação é um conjunto de tarefas com elevada inter-relação e com características e objetivos específicos. Os problemas de decisão que se colocam ao nível da ação são fundamentalmente diferentes dos que se colocam ao nível do cluster: enquanto os clusters requerem um planeamento estratégico a médio e longo prazo, as ações requerem um planeamento tático a curto prazo.

Dentro de um cluster, podem, por vezes, identificar-se linhas de investigação diferentes, que se focam em obter serviços ou produtos específicos e independentes entre si. Justifica-se, portanto, um tratamento analítico individual de cada uma destas linhas de investigação, até porque uma mesma linha pode ser partilhada por diferentes clusters, por haver necessidade de incorporar no mesmo produto ou serviço conhecimentos de áreas diferentes, e para duas linhas que pertençam totalmente ao mesmo cluster, pode ser 
favorável seguir uma delas e não outra. Este tipo de considerações fragiliza uma análise feita exclusivamente ao nível do cluster.

De forma a tratar estas linhas de investigação, foi definida uma nova entidade para as representar: o agregado. Sem existência formal na empresa, o agregado representa o que habitualmente se designa por projeto. A abordagem de avaliação desenvolvida baseia-se neste conceito que é, posteriormente, integrado nas estruturas formais existentes na empresa (as ações e os clusters).

Dividiram-se os agregados em dois tipos:

- "estratégico", em que se assumem objetivos de médio ou longo prazo,

- " de negócio", em que se considera importante a obtenção de lucros a curto prazo.

Esta diferenciação permite que cada tipo de agregado seja tratado de forma diferente, de acordo com as suas características específicas. No entanto, ambos os tipos de agregado são planeados, em geral, a médio prazo ( 4 ou 5 anos).

As ações têm como objetivo adquirir conhecimento, desenvolver e/ou integrar serviços ou soluções, prestar serviços de engenharia, entre outros. Foram identificados vários tipos de ações:

- Ações de investigação exploratória (tipo 1), que se destinam a explorar e dominar tecnologias, mesmo que não venham a ser imediatamente aplicadas. Este tipo de ação é, pois, destinada ao desenvolvimento e/ou obtenção de novas competências.

- Ações de desenvolvimento experimental (tipo 2), que têm uma aplicação bem definida, estão integradas numa linha de investigação definida, e que são relevantes para o avanço dessa mesma linha. A par de desenvolvimento, pode haver também a aquisição de competências.

- Ações de desenvolvimento de produto para venda imediata e serviços de engenharia (tipo 3), que visam desenvolver um produto ou serviço (para venda imediata) ou que visam fornecer apoio à utilização de um produto já desenvolvido. Estas ações têm uma forte componente comercial, ainda que continuem a incluir o desenvolvimento ou a manutenção de um produto ou serviço. Neste desenvolvimento, pode, por vezes, não haver um comprador definido, mas o objetivo será gerar interesse imediato e clientes. 
- Ações de gestão (tipo 4), que servem a estrutura organizacional da empresa, tais como ações ligadas à contabilidade ou ao planeamento. Devido à sua natureza, estas ações não foram integradas no processo de avaliação.

A diferenciação dos tipos de ações tornou-se essencial, pois cada tipo corresponde à prossecução de objetivos diferentes e a exigências diferentes de informação: por exemplo, uma ação do tipo 3 requer mais informação financeira do que uma ação dos tipos 1 ou 2. Na sequência de contactos com elementos da empresa, foi ainda estabelecido que se podem criar novos tipos de ações se vierem a surgir, no futuro, algumas ações que não se enquadrem em nenhum dos tipos definidos atrás.

No que se refere ao processo de decisão organizacional, a empresa possui diversos pontos de tomada de decisão: decisões tomadas a nível de direção/administração da empresa; decisões tomadas pelos responsáveis de projeto (a nível do agregado); e decisões tomadas pelos responsáveis pelas ações. No entanto, foram apenas identificados dois níveis de decisão ou escolha: o do agregado e o da ação. O ponto de decisão associado à direção/administração da empresa foi considerado através da parametrização de alguns critérios e ainda através da definição de agregados e ações típicas vistas como 'de referência'.

A abordagem de avaliação permite separar os dois níveis de decisão, sem esquecer a sua inter-relação. As decisões sobre a atribuição de recursos são separadas entre decisões estratégicas, quando da alocação dos recursos ao nível dos projetos (agregados), e decisões táticas, quando da alocação de recursos pelas ações que compõem cada agregado. Em ambos os níveis, foi definida uma estrutura hierárquica que é usada, em primeiro lugar, para definir e estruturar os critérios relevantes, e determinar as suas importâncias relativas. Estas importâncias ou pesos devem refletir as preferências institucionais, sendo assim, definidos por representantes da administração da empresa. A avaliação dos agregados e das ações nos diferentes critérios é feita pelos respetivos responsáveis. A partir destes dados e da importância dos critérios e subcritérios, obtém-se uma avaliação global do agregado ou da ação. A avaliação dos agregados serve de base a decisões gerais sobre alocação de recursos, enquanto a avaliação das ações serve de base a decisões sobre alocação de 
recursos dentro do respetivo agregado. A estrutura hierárquica considerada para as ações tem em conta a importância de cada ação no agregado correspondente, permitindo, assim, considerar a interdependência entre os dois níveis de avaliação.

Nas diferentes reuniões realizadas, constatou-se que a flexibilidade operacional se reveste de diferentes formas nos dois níveis de avaliação considerados. A flexibilidade operacional pode ser vista como a capacidade que a empresa tem para proceder a correções ou adaptações no decurso de um projeto, quando ocorrem acontecimentos que não eram expectáveis no cenário inicialmente considerado. A flexibilidade operacional adiciona valor ao projeto, maximizando os ganhos, se os desenvolvimentos ocorridos forem positivos, e minimizando as perdas, se esses desenvolvimentos forem negativos. É, pois, importante integrar a flexibilidade operacional na avaliação, de forma a incorporar corretamente o acréscimo de valor que a empresa terá, se responder de forma correta às situações que poderão ocorrer. As perspetivas relevantes sobre flexibilidade operacional diferem de acordo com os níveis de avaliação considerados.

A incorporação da flexibilidade operacional na avaliação dos agregados foi realizada através de subcritérios dos critérios operacionais e financeiros: flexibilidade da solução, dependência de terceiros, criticidade/escassez de recursos necessários, perda esperada por abandono e possibilidade de adiamento. A flexibilidade da solução refere-se à possibilidade de a solução adotada poder ser adaptada para utilizações diferentes das que estavam inicialmente previstas. A dependência de terceiros pretende penalizar agregados, cuja resposta a acontecimentos imprevistos, por parte da empresa, seja reduzida, por esta não controlar na totalidade o processo de desenvolvimento. Apesar de se valorizar a relação com terceiros, é necessário ter em conta que um maior controlo do processo de desenvolvimento por parte da empresa leva a uma maior capacidade de resposta a acontecimentos imprevistos. A criticidade/escassez de recursos necessários considera a contribuição do agregado para a diminuição da flexibilidade da empresa como um todo. A utilização de recursos escassos, por parte de um agregado, pode inviabilizar o desenvolvimento de outros projetos. Estes recursos podem referir- 
se, quer a pessoal muito especializado, quer a equipamentos muito específicos. A perda esperada por abandono considera a probabilidade de abandono e a perda que a empresa incorre no caso de abandono do projeto. Quanto maior a perda por abandono, mais irreversível será o projeto, e, portanto, menor será a flexibilidade operacional existente no mesmo. A probabilidade de abandono reflete a possibilidade de o projeto correr tão mal que valha a pena ser abandonado. A possibilidade de adiamento favorece o desenvolvimento rápido dos agregados que possam ser afetados por atrasos, podendo levar ao adiamento na alocação de recursos a agregados, cujo desenvolvimento possa sofrer menos com tal atraso. O adiamento pode, contudo, ter consequências positivas, como sendo a obtenção de mais informação, evitando o gasto desnecessário de recursos e permitindo o avanço com mais certeza de sucesso, ou o não avanço, em caso de ambiente desfavorável.

Estes subcritérios, espelhando as fontes de flexibilidade, foram os identificados nas reuniões com elementos da empresa. A abordagem permite, no entanto, se necessário, acrescentar outros subcritérios relacionados com outras fontes de flexibilidade. A importância da flexibilidade operacional difere consoante o tipo de agregado em consideração. Por exemplo, num agregado com características de negócio, a possibilidade de ajustamento rápido a uma situação imprevista é, em geral, mais importante do que num agregado com características mais estratégicas (as relações com terceiros, questões tecnológicas ou competências adquiridas serão mais importantes). Esta diferença de importância é tida em conta durante o processo de avaliação.

Para incorporar a flexibilidade operacional na avaliação das ações, os subcritérios identificados foram a dependência (operacional) de terceiros, criticidade/escassez de recursos necessários, perda esperada por abandono e a possibilidade de adiamento. A dependência (operacional) de terceiros é muito semelhante ao subcritério "dependência de terceiros" nos agregados. No entanto, para as ações, esta dependência é puramente operacional, já que no caso dos agregados, a dependência poderá ser "política", na medida em que o processo de decisão possa não ser exclusivo da PT Inovação. A criticidade/escassez de recursos necessários também é semelhante ao subcritério com o mesmo nome nos agregados, sendo que nas ações os 
recursos referem-se aos existentes dentro do agregado a que ação pertence. A perda esperada por abandono e a possibilidade de adiamento têm também uma definição semelhante à que foi feita para os agregados.

Repare-se que o subcritério flexibilidade de solução não se encontra nas ações, pois este subcritério refere-se a projetos globais e não tanto a tarefas mais específicas como aquelas que definem, em geral, as ações. Se forem identificadas outras fontes de flexibilidade, estas podem ser incorporadas através de novos subcritérios, como foi sugerido no caso dos agregados.

Também para as ações, a importância das fontes de flexibilidade é diferente mediante o tipo de ação considerada. Por exemplo, numa ação de desenvolvimento experimental é mais importante saber reagir a acontecimentos imprevistos do que numa ação de investigação exploratória. O modelo de avaliação incorpora estas diferenças de importância nos diversos subcritérios.

Durante o tempo de vida de um projeto, novas oportunidades de ações podem ocorrer ou pedidos inesperados de clientes podem acontecer. Estes acontecimentos não previstos e não contemplados na avaliação inicial requerem uma reafetação dos recursos dentro do agregado, e consequentemente, nas ações que o integram, para dar seguimento às oportunidades ou solicitações que podem aparecer. O modelo de avaliação apresentado permite a integração destas situações, através da sua aplicação intercalar dentro dos agregados. Assim, deve proceder-se à avaliação das novas solicitações ou oportunidades como novas ações; reavaliam-se as ações que mostrem diferenças significativas relativamente ao plano inicial; utilizam-se estas avaliações e reavaliações para decidir se se deve ou não empreender as novas ações, e caso esta decisão seja positiva, deve decidir-se sobre os recursos a alocar a estas novas ações e onde devem ser retirados recursos.

Assim, é possível reagir a novas situações a partir do modelo, de forma transparente, e usando a mesma estrutura de decisão utilizada inicialmente.

Após a avaliação dos agregados e a avaliação das ações que pertencem a cada agregado, é necessária a utilização de ferramentas que ajudem na alocação dos recursos de cada agregado pelas diferentes ações que o compõem. Pretende-se, pois, encontrar a melhor alocação de recursos que permita responder às prioridades que vão sendo criadas. Os recursos mais 
importantes na empresa são as pessoas, pelo que a avaliação apresentada pretende estabelecer a melhor alocação possível das pessoas às ações e agregados.

A avaliação das ações permite obter um valor de desempenho ou prioridade para cada ação. Este desempenho é então utilizado para determinar os recursos a atribuir a cada ação de entre os que foram atribuídos ao agregado a que as ações pertencem. Esta atribuição pode ser feita usando um de dois procedimentos:

1. Definição de prioridades (classificações) globais para cada ação, e seleção de ações por ordem de prioridade. Neste processo de seleção, podem existir restrições como níveis máximos e/ou mínimos de alocação.

2. Utilização de programação matemática por forma a maximizar a soma das prioridades das ações selecionadas, tendo em conta restrições de recursos e outras consideradas relevantes, como limites de utilização de recursos em cada tipo de ação, mínimos para a pontuação agregada em alguns critérios ou subcritérios, etc.

Estes procedimentos não substituem o papel e o julgamento dos decisores, mas antes completam e ajudam na tomada de decisões, já que tais procedimentos dão indicações valiosas, não descurando da sensibilidade dos decisores para eventuais ajustes na construção de um portfólio equilibrado de ações.

\section{Estrutura e desenvolvimento da solução proposta}

Nesta secção, descreve-se a estrutura da solução proposta, bem como as técnicas utilizadas para proceder à avaliação dos agregados e das ações. A avaliação dos agregados e a avaliação das ações baseiam-se em estruturas hierárquicas, e, a partir destas estruturas, são calculados os pesos dos critérios e subcritérios. O cálculo dos pesos dos critérios e subcritérios é feito com base no método AHP. A avaliação dos agregados e das ações em cada critério e subcritério também é feita com base no método AHP. No entanto, quando se consideram valores financeiros, a avaliação dos agregados e das ações pressupõe um tratamento especial, de forma a encontrar uma avaliação comparável à que se obtém quando se aplica o método AHP em critérios e 
subcritérios não financeiros, e também para garantir um tratamento uniforme dos valores financeiros em todas as ações e agregados. Para evitar um grande número de comparações, quando se infere o peso dos critérios e dos subcritérios ou as prioridades dos agregados ou ações, são utilizadas matrizes incompletas de comparações (Harker, 1987).

Após a determinação das prioridades dos agregados e das ações de cada agregado, é necessário encontrar ferramentas que ajudem na alocação dos recursos a cada ação de entre os recursos atribuídos ao respetivo agregado.

\subsection{A estrutura da solução proposta}

A avaliação dos agregados resulta na atribuição de uma prioridade a cada um, sendo que uma maior prioridade equivale a uma maior atratividade do agregado, e portanto, maior será o grau de satisfação com a alocação de recursos. A determinação destas prioridades baseia-se numa estrutura hierárquica.

Tabela 1 - Critérios e subcritérios na hierarquia dos agregados

\begin{tabular}{|c|c|c|c|}
\hline Critérios & Estratégico & Operacional & Financeiro \\
\hline Subcritérios & $\begin{array}{l}\text { - Contribuição para a } \\
\text { imagem da empresa } \\
\text { - Liderança do mercado } \\
\text { - Competências } \\
\text { adquiridas } \\
\text { - Parcerias estratégicas } \\
\text { - Importância da } \\
\text { credibilidade da empresa } \\
\text { junto do cliente } \\
\text { - Importância da } \\
\text { tecnologia desenvolvida } \\
\text { para o grupo PT }\end{array}$ & $\begin{array}{l}\text { - Incerteza técnica } \\
\text { - Criticidade/escassez } \\
\text { dos recursos } \\
\text { necessários } \\
\text { - Flexibilidade da } \\
\text { solução } \\
\text { - Dependência de } \\
\text { terceiros } \\
\text { - Satisfação imediata } \\
\text { do cliente }\end{array}$ & $\begin{array}{l}\text { - Valor financeiro (valor } \\
\text { atual líquido de } \\
\text { médio/longo prazo, ou } \\
\text { valor atual líquido a um } \\
\text { ano + perspetivas de } \\
\text { crescimento + tendência } \\
\text { de mercado) } \\
\text { - Perda esperada por } \\
\text { abandono } \\
\text { - Possibilidade de } \\
\text { adiamento }\end{array}$ \\
\hline
\end{tabular}


A estrutura hierárquica para a avaliação dos agregados é a seguinte: no primeiro nível estão os tipos de agregado. A classificação utilizada, como descrito anteriormente, divide os agregados em "tipo estratégico", em que se assumem objetivos de médio ou longo prazo, e "tipo negócio", em que se considera importante a obtenção de lucros a curto prazo. Esta diferenciação permite que cada tipo de agregado seja tratado de forma diferente, de acordo com as suas características específicas.

No segundo nível, encontram-se os critérios. Nas reuniões realizadas, obtiveram-se três critérios: estratégico, operacional e financeiro. No terceiro nível da hierarquia, encontram-se os subcritérios, que estão definidos na Tabela 1. Alguns destes subcritérios correspondem aos critérios que refletem a flexibilidade operacional. Finalmente, no último nível da hierarquia, encontram-se os agregados.

A avaliação das ações baseia-se num processo semelhante ao dos agregados, resultando na atribuição de uma prioridade a cada uma. Os valores destas prioridades serão utilizados para determinar os recursos atribuídos a cada ação, de entre os recursos que foram atribuídos ao agregado a que a ação pertence.

Tabela 2 - Critérios e subcritérios na hierarquia das ações

\begin{tabular}{|l|l|l|l|}
\cline { 2 - 4 } Critérios & Estratégico & Operacional & Financeiro \\
\hline \multirow{5}{*}{ Subcritérios } & - Contribuição para a & - Incerteza técnica & - Valor financeiro \\
& imagem da empresa & - Criticidade/escassez dos & (valor atual líquido a \\
& - Liderança do mercado & recursos necessários & um ano) \\
& - Competências & - Dependência & - Perspetivas de \\
& adquiridas & (operacional) de terceiros & crescimento \\
& - Importância da & o agregado & - Tendência de \\
& satisfação do cliente & & mercado \\
& - Importância da & & - Perda esperada por \\
& tecnologia desenvolvida & & abandono \\
para o grupo PT & & - Possibilidade de \\
\cline { 2 - 4 } & & & adiamento \\
\hline
\end{tabular}


A determinação destas prioridades baseia-se também numa estrutura hierárquica, onde no primeiro nível estão os tipos de ação. Relembre-se que, na avaliação, não constam as ações do tipo 4. Esta diferenciação permite que cada tipo de ação seja tratado de forma diferente, de acordo com as suas características específicas. No segundo nível da hierarquia, encontram-se os critérios, cuja identificação é a mesma do que no caso dos agregados: estratégico, operacional e financeiro. No terceiro nível da hierarquia, encontram-se os subcritérios, que estão identificados na Tabela 2. Como no caso dos agregados, alguns destes subcritérios correspondem aos critérios identificados que refletem a flexibilidade operacional. Finalmente, no último nível da hierarquia, encontram-se as ações.

Após a determinação dos pesos dos critérios e dos subcritérios, cada agregado (respetivamente ação) é avaliado em cada subcritério. Para os subcritérios qualitativos ou intangíveis, a determinação das prioridades dos agregados/ações, em cada subcritério, é feita de forma semelhante à utilizada para inferir os pesos dos critérios e os pesos dos subcritérios, que é explicada, em detalhe, na secção 3.2. A avaliação dos agregados/ações, nos subcritérios tangíveis, que correspondem aos subcritérios financeiros, é explicada na secção 3.3, sendo que o resultado dessa avaliação corresponde, como nos restantes subcritérios, a prioridades. A prioridade global, $G$, dos agregados/ações corresponde à agregação das prioridades dos elementos, em cada subcritério, com os pesos dos critérios e com os pesos dos subcritérios. Isto é, a prioridade global de uma ação/agregado de índice $k$ é:

$$
G_{k}=\sum_{j=1}^{n c r i t} W_{j}\left(\sum_{i=1}^{n s_{j}}\left(W_{i j} W_{i j k}\right)\right)
$$

onde:

ncrit é o número de critérios presentes no nível 2 da hierarquia;

$W_{j}$ é o peso do critério de índice $j$ do nível 2 da hierarquia, $j=1, \ldots, n c r i t$;

$n s_{j}$ é o número de subcritérios do nível 3 da hierarquia referente ao critério de índice $j, j=1, \ldots$, ncrit ; 
$W_{i j}$ é o peso do subcritério de índice $i$ do nível 3 da hierarquia pertencente ao critério de índice $j, i=1, \ldots, n s_{j}, j=1, \ldots$, ncrit;

$W_{i j k}$ é a prioridade do agregado/ação, de índice $k$, em relação ao subcritério de índice $i$ do nível 3 da hierarquia que pertence ao critério de índice $j, i=1, \ldots, n s_{j}, j=1, \ldots$, ncrit.

Note-se que esta agregação é aditiva e a sua utilização pressupõe a independência preferencial dos critérios e subcritérios, ou seja, é necessário que as preferências num critério ou subcritério, ou num grupo de critérios ou subcritérios, não sejam afetadas pelas preferências noutros critérios ou subcritérios. A independência preferencial dos critérios é garantida pela forma como foi definida a estrutura hierárquica e os seus elementos: ao incluir, num primeiro nível, o tipo de agregado e ação, foi possível garantir esta independência. Note-se que, sem incluir este primeiro nível era possível que ocorressem violações da independência preferencial: em agregados com uma prioridade elevada no critério estratégico, uma pontuação alta no critério operacional e baixa financeiro podia ser preferível a uma pontuação baixa no primeiro critério e alta no segundo; no entanto, se a prioridade do critério estratégico for baixa, estas preferências poderiam inverter-se. Ao definir o tipo de agregado, que indica qual a vocação prioritária de cada agregado, esta possível dependência desaparece. Um raciocínio semelhante podia também ser feito para as ações. Por outro lado, para os subcritérios, houve o cuidado de os definir por forma a que dois subcritérios meçam características diferentes que não apresentem dependência entre si.

\subsection{Determinação dos pesos dos critérios em cada nível das hierarquias}

Para proceder à avaliação, é necessário, numa primeira fase, definir os pesos de cada critério e subcritério. A determinação dos pesos é feita com base no método AHP. Para tal, o responsável de decisão em cada nível deve fazer comparações entre os critérios. No procedimento apresentado, esse responsável precisa apenas de fazer algumas comparações, evitando, assim, requerer-lhe demasiada informação. Este procedimento é baseado na inferência dos pesos dos critérios, a partir de uma matriz de comparações incompleta 
(Harker, 1987): o responsável preenche, então, parte de uma matriz de comparações, $A=\left[a_{i j}\right]_{i, j=1, \ldots, n}$, onde n é o número de critérios (subcritérios) e $a_{i j}$ representa a comparação entre o critério $i$ e o critério $j$.

Para uma matriz completa de comparações, é usual utilizar o modelo AHP original de Saaty, na determinação do peso dos critérios. Este método também analisa a coerência das comparações feitas, isto é, uma matriz completada por um agente de decisão pode conter alguma incoerência devida à possível existência de intransitividade entre as comparações. Saaty (1994b) propôs a medição da incoerência, através do índice de coerência $(C I)$, definido por

$$
C I=\frac{\lambda_{\text {max }}-n}{n-1}
$$

onde $\lambda_{\max }$ representa o valor próprio de maior norma da matriz de comparações. A interpretação do índice de coerência depende do tamanho da matriz (n). Saaty (1994b) propôs dividir o índice de coerência pela média de índices de coerência de matrizes de comparações geradas aleatoriamente. Este valor médio é designado por índice de coerência aleatório $(R I)$ e o quociente entre $C I$ e $R I$ é designado como rácio de coerência $(C R)$ e é interpretado como a percentagem de incoerência na matriz de comparações (Godinho e Outros, 2011). Em geral, considera-se que a incoerência é aceitável para um rácio de coerência de valor máximo de 10\%.

Ora, no caso de uma matriz incompleta, existem duas possibilidades no seu preenchimento: preencher $n$-1 comparações ou mais do que $n$ - 1 comparações, mantendo a matriz incompleta.

Para inferir, de forma coerente, todos os restantes valores da matriz de comparações, a partir de n-1 comparações, é suficiente que essas $n$-1 comparações estejam em colunas diferentes da matriz, e apenas num dos triângulos. Note-se que, por exemplo, numa matriz de comparações em que $a_{j k}=r$ e $a_{j h}=s$, então, temos que $a_{k h}=s / r$ e $a_{h k}=r / s$. Neste sentido, é possível inferir todos os valores da matriz de comparações de forma coerente. Numa matriz de comparações totalmente coerente, o valor próprio máximo é $n$, e o seu vetor próprio associado normalizado corresponde às prioridades das alternativas em comparação. Seja ele $W=\left[\begin{array}{llll}W_{1} & W_{2} & \ldots & W_{n}\end{array}\right]$. Numa matriz de 
comparações totalmente coerente, $a_{i j}=W_{i} / W_{j}, i=1, \ldots, n$ e $j=1, \ldots, n$, e o índice de coerência é, naturalmente, 0 (Kablan, 2004).

Quando existem mais do que $n$-1 comparações, pode acontecer que a matriz de comparações não seja totalmente coerente, mesmo se for incompleta. Para inferir prioridades a partir de matrizes incompletas, foi utilizado o método apresentado por Harker (1987). O método começa por criar uma matriz nova $F$, baseada na matriz incompleta de comparações $A$. A matriz $F$ é definida da seguinte forma:

$$
f_{i j}=\left\{\begin{array}{l}
a_{i j}, \text { se } a_{i j}>0 \text { e } i \neq j \\
\text { número de células vazias da linha } i, \text { se } i=j \\
0, \text { caso contrário }
\end{array}\right.
$$

O vetor próprio normalizado associado ao valor próprio máximo da matriz $F+I$, onde $I$ representa a matriz identidade, é uma aproximação do vetor das prioridades das alternativas. Com este vetor de prioridades, pode calcular-se o rácio de coerência e perceber se se devem ou não rever julgamentos. Se a matriz for suficientemente coerente, pode utilizar-se o vetor de prioridades assim calculado.

\subsection{Tratamento de subcritérios financeiros}

Para os subcritérios financeiros, como sendo o VAL ou outra perspetiva financeira, considerou-se que a forma como os valores financeiros são convertidos para prioridades devia refletir as preferências organizacionais, e não ser feito de forma casuística consoante as ações ou agregados a serem avaliados. A solução encontrada passou por definir valores financeiros de referência, com o apoio da gestão de topo da empresa. A comparação entre estes valores financeiros de referência é, também, feita pela gestão de topo da empresa.

O intervalo que contém os valores financeiros de referência deve ter uma amplitude, tal que, qualquer previsão para valores financeiros de um agregado ou ação deva estar no interior desse intervalo. Assume-se também que as preferências são lineares para todos os valores pertencentes ao intervalo entre dois valores de referência consecutivos. Esta hipótese permite construir uma 
matriz ampliada de comparações com os valores financeiros de referência e com os valores financeiros para ações ou agregados. A partir dessa matriz de comparações, que pode ser incompleta, e aplicando o mesmo procedimento da secção anterior, é possível inferir as prioridades de todos os valores. Retirando apenas as prioridades dos valores financeiros das ações ou agregados, normalizam-se essas prioridades e obtém-se um vetor de prioridades para os valores financeiros das ações ou agregados em avaliação. Estas prioridades normalizadas podem ser utilizadas de forma idêntica às prioridades que se obtêm nos outros subcritérios não tangíveis.

Apresenta-se agora um exemplo simples. Quer este exemplo quer a sua apresentação seguem de perto Godinho e Outros (2011). Suponha-se que os valores de referência são -100, 0 e +100. A matriz de comparações é a seguinte:

\begin{tabular}{|c|c|c|c|}
\hline & -100 & 0 & 100 \\
\hline-100 & {$[1$} & $1 / 3$ & $1 / 6$ \\
\hline 0 & 3 & 1 & $1 / 2$ \\
\hline 100 & 6 & 2 & 1 \\
\hline
\end{tabular}

Esta matriz de comparações leva às seguintes prioridades para os valores de referência: $W=\left[\begin{array}{lll}0.10 & 0.30 & 0.60\end{array}\right]$, respetivamente para os valores -100 , 0 e 100 . Introduzam-se, agora, dois valores financeiros, -25 e 50 . Assim, tendo em conta as prioridades dos valores de referência e assumindo a linearidade entre as preferências dos valores de referência -100 e 0 , tem-se que, como $-25=-100+0.75(0-(-100))$, então a prioridade do valor de -25 é $0.1+0.75(0.30-0.10)=0.25$. Analogamente, pode determinar-se a prioridade do valor 50. Ora, 50=0+0.50(100-0). Assumindo a linearidade nas preferências dos valores de referência, a prioridade do valor 50 é $0.30+0.50(0.60-0.30)=0.45$.

Com esta informação, pode construir-se uma matriz ampliada de comparações que inclui os valores de referência e os valores financeiros introduzidos. A partir das prioridades encontradas, podem determinar-se as comparações par a par entre todos os valores de referência e cada um dos valores financeiros introduzidos. Por exemplo, a comparação entre o valor -100 e o valor -25 será o quociente entre a prioridade de -100 e a prioridade encontrada de -25. Isto é, a comparação entre -100 e -25 será 0.1/0.25. O 
mesmo raciocínio se aplica nas comparações entre os valores de referência e cada um dos novos valores introduzidos (-25 e 50). Note-se que muito dos valores resultantes das comparações não pertencem à escala definida pelo método AHP (inteiros positivos de 1 a 9 e seus inversos). No entanto, de acordo com Saaty (1997), a escala por ele definida é apenas indicativa e serve para ajudar os agentes de decisão a estabelecerem comparações. Mas se outros valores entrarem na matriz de comparações, o procedimento para encontrar as prioridades das alternativas mantém-se. A matriz ampliada de comparações será, então

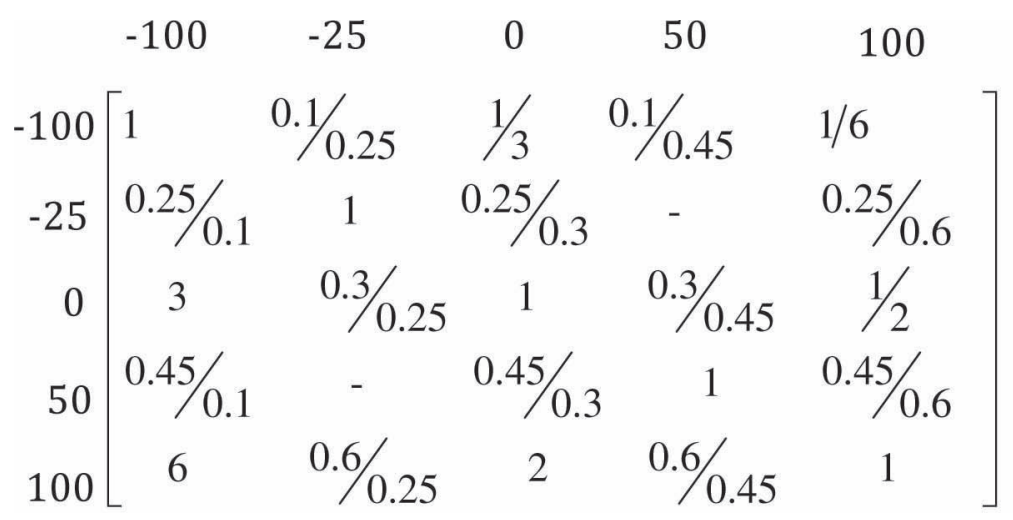

Esta matriz de comparações não está completa, pois não foram introduzidas as comparações entre os valores financeiros introduzidos -25 e 50. Aplicando o procedimento apresentado por Harker (1987), para matrizes incompletas de comparações, é possível inferir as prioridades de cada um dos valores.

A partir da metodologia apresentada por Harker (1987), obtém-se o seguinte vetor de prioridades ou importâncias relativas: [0.059 0.147 0.1760 .265 0.353]. Como só existe interesse nas prioridades dos valores financeiros de -25 e 50, as prioridades correspondentes podem ser normalizadas, de forma a que a sua soma seja 1 , levando a que a prioridade do valor de -25 seja 0.357 e a que a prioridade do valor de 50 seja de 0.643 .

Neste exemplo, o vetor de prioridades apresentado acima podia ainda ser obtido por simples normalização do vetor que inclui as prioridades inicialmente determinadas para os valores de referência e para os valores 
financeiros a avaliar, isto é, por simples normalização do vetor [ $\begin{array}{lll}0.10 & 0.25 & 0.30\end{array}$ 0.45 0.60], não sendo necessário recorrer à segunda matriz de comparações. No entanto, isto ocorre apenas quando a matriz de comparações dos valores de referência apresenta perfeita coerência, isto é, quando o seu índice de coerência é nulo. No caso geral, quando não se pode assumir que a matriz de comparações dos valores de referência é perfeitamente coerente, é necessário efetuar todo o procedimento descrito.

Note-se que, por forma a definir de forma mais detalhada as preferências relativas a valores financeiros é necessário incluir um maior número de valores de referência. Na implementação efetuada na empresa, o processo foi simplificado pelo facto de os representantes deste terem dado a indicação de que se podiam assumir preferências lineares entre valores financeiros positivos. Com este pressuposto, basta incluir no conjunto de valores de referência o valor zero e um (ou nenhum) valor positivo. Se existir um valor positivo nos valores de referência, as prioridades correspondentes a este valor e ao valor zero definem uma linha de tendência que permite realizar todas as comparações que envolvem valores positivos na matriz ampliada. Se não for incluído nenhum valor positivo, então a linha de tendência usada para definir as comparações com valores positivos recorre às preferências relativas ao valor zero e ao maior valor de referência negativo.

\subsection{Alocação dos recursos às ações de cada agregado}

Após a avaliação dos agregados e das ações, torna-se necessário encontrar ferramentas que ajudem na alocação dos recursos às ações que compõem cada agregado. Note-se que, no caso dos agregados, a solução implementada prevê que a distribuição de recursos tenha em consideração a sua avaliação, mas não foi definida uma regra explícita de distribuição, uma vez que pode ser razoável atribuir preferencialmente recursos de tipo diferente a agregados diferentes.

As prioridades globais encontradas para cada ação, $G_{k}, k=1, \ldots, n$, sendo $n$ o número de ações avaliadas, no processo de avaliação, podem servir de base à alocação de recursos. A atribuição dos recursos a cada ação pode ser feita através da seleção das ações por ordem das prioridades globais encontradas. Num tal procedimento, pode ainda impor-se que as ações de cada 
tipo tenham uma quantidade mínima e uma quantidade máxima de recursos alocados. Neste procedimento, mais simples, as ações com prioridades mais altas são selecionadas e veem, em primeiro lugar, as suas necessidades satisfeitas, em termos de recursos.

A programação matemática também é uma alternativa para encontrar a melhor alocação de recursos às ações de cada agregado. Na formulação de um tal problema, a função objetivo deve conduzir à maximização da prioridade global das ações selecionadas para o agregado, e as restrições devem definir que a quantidade máxima a alocar é aquela que foi estabelecida para o agregado. Em geral, existem vários tipos de recurso que podem ser atribuídos às ações. Cada ação pode precisar de quantidades específicas de cada tipo de recursos. Neste caso, suponha-se que existem $N$ tipos de recurso com quantidades disponíveis de $Q_{j}, j=1, \ldots, N$. Para cada nível de recursos $j$, assume-se que cada ação $k$ necessita de uma quantidade $q_{k j}$ para ser executada, $k=1, \ldots, n ; j=1, \ldots N$.

Neste caso, o problema a resolver é

$$
\begin{array}{ll}
\max & \sum_{k=1}^{n} G_{k} y_{k} \\
\text { s.a. } & \sum_{k=1}^{n} q_{k j} y_{k} \leq Q_{j}, j=1, \ldots, N \\
& y_{k} \in\{0,1\}, k=1, \ldots, n
\end{array}
$$

sendo $y_{k}$ uma variável dicotómica, que assume o valor 1 se a ação de índice $k$ for selecionada, e 0 se não for. Num agregado, podem existir outras relações de dependência entre as ações a empreender, que podem ser representadas através de outras restrições. Por exemplo, se a ação 3 apenas puder ser empreendida se a ação 1 também o for, a restrição a incluir será $y_{1} \geq y_{3}$; se, de entre as ações 1 e 3 , só uma puder ser selecionada, a restrição será $y_{1}+y_{3} \leq 1$, etc.

Podem, ainda, definir-se outros tipos de restrições relevantes para cada agregado, tais como estabelecer mínimos para as prioridades em diferentes subcritérios, incluir restrições relativas a tipos de recursos especialmente 
escassos (por exemplo, relativas a equipamentos, que existam em quantidades muito limitadas na empresa), incluir limites relativos às ações de cada tipo a selecionar, entre outras que possam surgir. Este tipo de restrições é, também, linear e pode, facilmente, incluir-se no(s) problema(s) acima descrito(s).

\section{Utilização da solução proposta}

Antes da avaliação dos agregados e das ações, é necessário definir o peso dos critérios e dos subcritérios de cada uma das hierarquias definidas, respetivamente, para os agregados e para as ações. É importante que a avaliação passe por diferentes níveis de decisão em toda a organização para que possa corresponder às necessidades da empresa. Assim, a definição dos pesos dos critérios deve ser feita pela gestão de topo, já que, para diferentes tipos de agregados e diferentes tipos de ações, a importância desses critérios é diferente. Esta diferenciação deve-se aos diferentes objetivos que os agregados e as ações possam ter (mais relacionados com a área de negócio ou mais relacionados com a área de investigação e desenvolvimento, onde é mais preponderante a aquisição de novas competências).

Em cada nível de decisão das hierarquias, os respetivos responsáveis, através do seu conhecimento sobre os interesses e motivação de cada tipo de agregado/ação, podem fazer comparações entre os critérios (subcritérios), para que, através dos métodos descritos na secção anterior, se possam obter os pesos de cada um desses critérios (subcritérios).

Após a definição dos pesos de todos os critérios e subcritérios em ambas as hierarquias, pode proceder-se à avaliação dos agregados e das ações que os compõem. Esta avaliação baseia-se na obtenção das prioridades de cada agregado/ação em cada subcritério, definida a partir de um conjunto de comparações. Com estas prioridades e com os pesos dos critérios e subcritérios, é possível determinar a prioridade global de cada um dos agregados/ações do conjunto em avaliação.

Embora a solução implementada permita o tipo de comparações comum no AHP, isto é, a comparação de cada agregado/ação com os restantes em cada subcritério, foi definida uma outra alternativa de avaliação, cuja utilização se considera mais recomendável no contexto da empresa considerada. Esta 
avaliação tem por base um conjunto de agregados ou ações de referência, que são agregados ou ações fictícios, definidos pela administração, que representam os tipos de agregados e ações que usualmente são considerados na empresa. As comparações entre agregados de referência, e entre ações de referência, são definidos pela administração, permitindo a esta definir padrões que reflitam as políticas da empresa.

Quando se utilizam estes agregados (ações) de referência, é possível proceder à avaliação de cada agregado (ação) individualmente. O agregado/ação em avaliação individual é comparado com as referências nos diferentes subcritérios, a partir das metodologias apresentadas anteriormente, evitando, assim, um número elevado de comparações. O valor a reter do resultado da avaliação será o desempenho global do agregado ou ação em avaliação. Se vários agregados/ações forem avaliados individualmente em relação às referências, os valores resultantes dessas avaliações podem indicar o nível de atratividade de cada agregado/ação. Note-se que, quando a solução é utilizada desta forma, o problema de alteração da ordem das alternativas quando da introdução de uma nova alternativa, referido na Introdução, não ocorre.

Os agregados (ações) de referência podem também ser usados para avaliar simultaneamente vários agregados (ações). Neste caso, mesmo se o gestor tiver dificuldade em comparar entre si os agregados (ações) em avaliação, não necessita de o fazer - apenas necessita de comparar cada agregado/ação em avaliação com pelo menos uma referência e construir matrizes amplas e incompletas de comparações, que incluem as referências e os agregados em avaliação. Para cada subcritério, o vetor das prioridades inclui, quer as referências, quer os agregados/ações em avaliação, mas devem reter-se e normalizar-se as prioridades dos agregados/ações em avaliação. Note-se que, nesta forma de utilização da solução poderá, novamente, ocorrer o problema de alteração da ordem das alternativas quando da introdução de uma nova alternativa.

A avaliação de um conjunto de ações/agregados, usando ou não as referências, conduz a uma avaliação relativa dos seus elementos. Os valores assim obtidos serão a base para a alocação dos recursos humanos entre os 
diferentes agregados e para a alocação de recursos entre as diferentes ações que compõem um agregado. Além disso, é possível, com a avaliação de um conjunto de agregados, ter uma noção sobre o nível de atratividade de cada um, e uma orientação para a atribuição de recursos a estes.

\section{Exemplo de aplicação}

Nesta secção, apresenta-se um exemplo de aplicação, para a avaliação de dois agregados, com base num conjunto de referências. Suponhamos que se pretendem avaliar dois agregados do tipo estratégico, Ag1 e Ag2, e que existem 3 agregados de referência, Ref1, Ref2 e Ref3. As referências foram definidas e comparadas, em todos os subcritérios, pela administração de acordo com as políticas da empresa. Como foi referido atrás, existem duas possibilidades para avaliar os dois agregados em relação às referências: em cada subcritério, compara-se, individualmente, cada agregado com as referências, utilizando duas matrizes de comparações, ou constrói-se uma matriz ampla de comparações. Esta matriz ampla de comparações deve conter já as comparações entre as referências (fornecidas aquando da sua definição) e, portanto, o responsável pela avaliação apenas tem que comparar cada agregado com, pelo menos, uma das referências, sem ter que comparar os agregados entre si. Suponha-se que a matriz de comparações das referências, no subcritério competências adquiridas relativo ao critério estratégico, é a seguinte:

\section{Ref1 Ref2 Ref3}

Ref1
$\operatorname{Ref2} 2$$\left[\begin{array}{ccc}1 & 1 / 3 & 1 / 6 \\ 3 & 1 & 1 / 2 \\ 6 & 2 & 1\end{array}\right]$

O agente de decisão não necessita, como foi referido, de fazer todas as comparações entre as referências e os agregados em avaliação. O responsável apenas tem que inserir, pelo menos, uma comparação, entre cada agregado em avaliação e uma das referências. Suponha-se que a matriz ampla de 
comparações contém as comparações entre cada agregado em avaliação e as referências, mas não a comparação direta entre ambos os agregados:

\begin{tabular}{|c|c|c|c|c|c|}
\hline & Ref1 & Ref2 & Ref3 & Ag1 & Ag2 \\
\hline Ref1 & {$[1$} & $1 / 3$ & $1 / 6$ & $1 / 3$ & $1 / 3$ \\
\hline Ref2 & 3 & 1 & $1 / 2$ & $1 / 4$ & 3 \\
\hline Ref3 & 6 & 2 & 1 & 1 & 2 \\
\hline Ag1 & 3 & 4 & 1 & 1 & - \\
\hline Ag2 & 3 & $1 / 3$ & $1 / 2$ & - & 1 \\
\hline
\end{tabular}

Aplicando a metodologia de Harker (1987), obtém-se o seguinte vetor de prioridades para este subcritério: [Ref1 Ref2 Ref3 Ag1 Ag2]=[0.06 0.175 0.297 0.351 0.116]. Como apenas se pretendem as prioridades dos agregados em avaliação, fazendo a normalização das prioridades dos agregados, vem que [Ag1 Ag2] $=\left[\begin{array}{ll}0.75 & 0.25\end{array}\right]$. Em todos os subcritérios não tangíveis (qualitativos), adota-se esta metodologia. Em relação ao subcritério tangível (financeiro) adota-se a metodologia apresentada na subsecção 3.3. Para agregar todas as prioridades e poder calcular a prioridade global para cada agregado, suponhase que os três critérios, estratégico, operacional e financeiros, têm os seguintes pesos, respetivamente, $\left.\begin{array}{lll}0.5 & 0.3 & 0.2\end{array}\right]$. Suponha-se ainda os seguintes pesos para os subcritérios de cada critério:

Estratégico: $\left[\begin{array}{llllll}0.20 & 0.15 & 0.20 & 0.15 & 0.10 & 0.20\end{array}\right]$, para os subcritérios respetivos, apresentados na Tabela 1 .

Operacional: $\left[\begin{array}{lllll}0.20 & 0.15 & 0.25 & 0.20 & 0.20\end{array}\right]$, para os subcritérios respetivos, apresentados na Tabela 1.

Financeiro: $\left[\begin{array}{lll}0.40 & 0.30 & 0.30\end{array}\right]$, para os subcritérios respetivos, apresentados na Tabela 1.

A metodologia apresentada para calcular as prioridades dos agregados no subcritério competências adquiridas é repetida para os restantes subcritérios não tangíveis. Para o subcritério tangível, é seguida a metodologia já apresentada (subsecção 3.3). Suponha-se, então, que as prioridades para cada um dos subcritérios são as apresentadas na Tabela 3. Agregando as prioridades 
com os pesos dos subcritérios e dos critérios, temos que as prioridades globais dos agregados são, respetivamente, $G_{A g 1}=0.513 \mathrm{e} G_{A g 2}=0.487$.

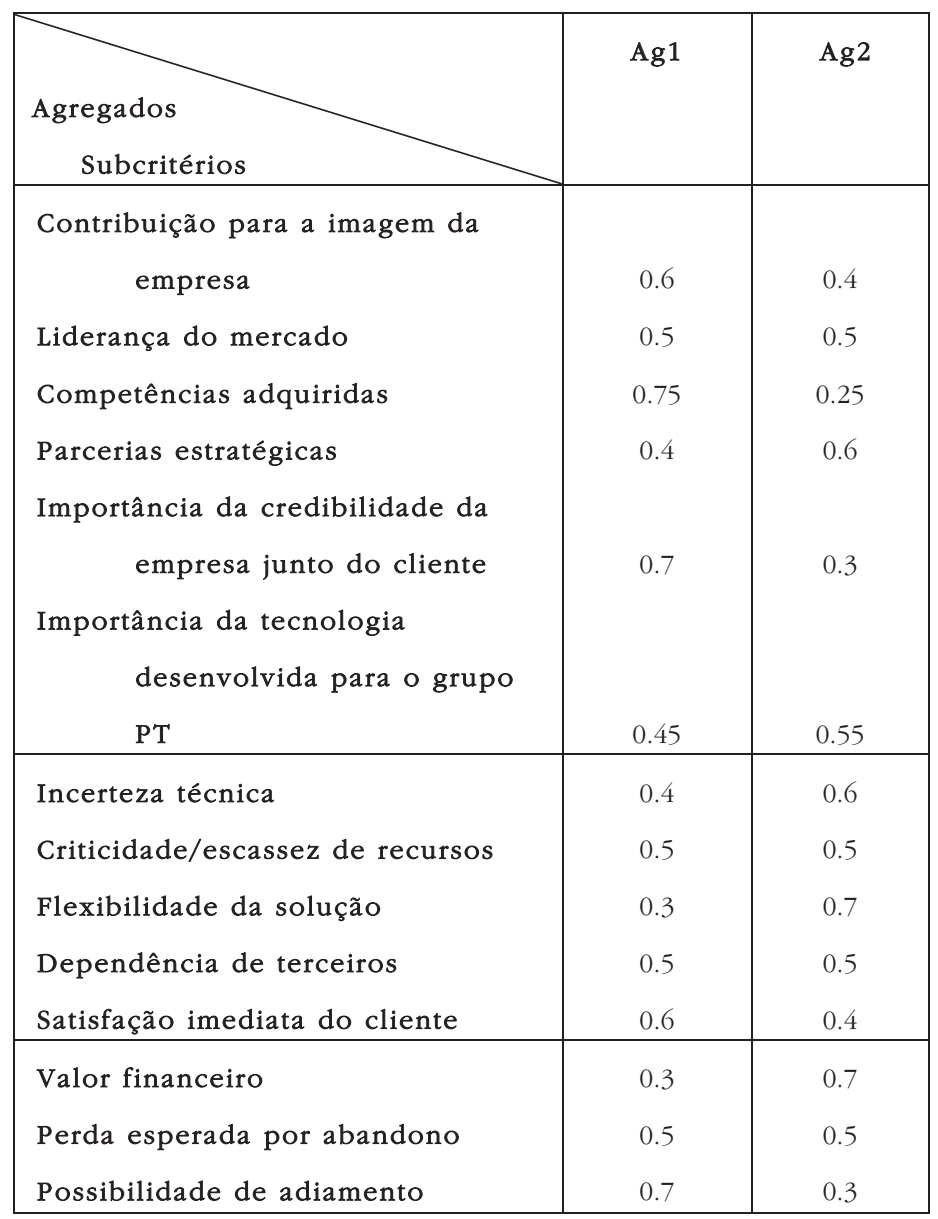

Tabela 3 - Prioridades dos agregados nos diferentes subcritérios

É necessário distribuir os recursos existentes pelos dois agregados. Suponha-se que existem três tipos de recurso, $T_{1}, T_{2}$ e $T_{3}$, representando três perfis de mão-de-obra, com competências diferenciadas. A disponibilidade dos três tipos de recursos é, respetivamente, $q_{1}=100 ; q_{2}=200 ; q_{3}=250$ (valores em homens.mês). Como foi indicado na subsecção 3.4, não foi definida uma regra explícita de distribuição de recursos pelos agregados. Assim, vamos supor que, tendo em conta avaliação global do agregado Ag1, as características deste e a 
quantidade global de recursos existente, foi decidido atribuir a este 58 homens.mês do tipo $T_{1}, 117$ homens.mês de $T_{2}$ e 146 homens.mês de $T_{3}$, e que este agregado tem 5 ações que podem ser empreendidas, $A c_{1}, A c_{2}, A c_{3}, A c_{4}, A c_{5}$. Na Tabela 4, apresentam-se as necessidades de cada ação em relação a cada tipo de recurso, bem como as prioridades que se obtiveram, depois de aplicado o processo de avaliação (em tudo semelhante ao que foi explicado para os agregados).

\begin{tabular}{|c|c|c|c|c|}
\hline Ação & $\begin{array}{c}\text { Quant. necessária } \\
\text { de } T_{1}\end{array}$ & $\begin{array}{c}\text { Quant. necessária de } \\
T_{2}\end{array}$ & $\begin{array}{c}\text { Quant. necessária de } \\
T_{3}\end{array}$ & $\begin{array}{c}\text { Prioridade da } \\
\text { ação }\end{array}$ \\
\hline$A c_{1}$ & 10 & 20 & 25 & 0.125 \\
\hline$A c_{2}$ & 15 & 30 & 36 & 0.201 \\
\hline$A c_{3}$ & 10 & 12 & 20 & 0.089 \\
\hline$A c_{4}$ & 18 & 36 & 45 & 0.325 \\
\hline$A c_{5}$ & 11 & 20 & 30 & 0.260 \\
\hline
\end{tabular}

Tabela 4 - Quantidades necessárias de recursos e prioridades das ações

Com estes dados, e assumindo que não se pretendem definir limites para as ações de cada tipo a implementar nem outras restrições, o programa linear a resolver para selecionar as ações a empreender do agregado Ag1 seria o seguinte:

$$
\begin{array}{ll}
\max & 0.125 y_{1}+0.201 y_{2}+0.089 y_{3}+0.325 y_{4}+0.260 y_{5} \\
\text { s.a. } & 10 y_{1}+15 y_{2}+10 y_{3}+18 y_{4}+11 y_{5} \leq 58 \\
& 20 y_{1}+30 y_{2}+12 y_{3}+36 y_{4}+20 y_{5} \leq 117 \\
& 25 y_{1}+36 y_{2}+20 y_{3}+45 y_{4}+30 y_{5} \leq 146 \\
& y_{i} \in\{0,1\} \quad i=1, \ldots, 5
\end{array}
$$

A solução ótima deste problema é $\left[\begin{array}{lllll}y_{1} & y_{2} & y_{3} & y_{4} & y_{5}\end{array}\right]=\left[\begin{array}{lllll}1 & 1 & 0 & 1 & 1\end{array}\right]$. Para o responsável pelo agregado Ag1, as ações a executar seriam $A c_{1}, A c_{2}, A c_{4}, A c_{5}$. 
Note-se que, no final do procedimento, é normal que as ações selecionadas não utilizem a totalidade dos recursos disponíveis, pois haverá quantidades residuais dos recursos que sobram em cada agregado - no caso do exemplo, é fácil ver que ficam por utilizar 4 homens.mês do tipo $T_{1}, 11$ homens.mês de $T_{2}$ e 10 homens.mês de $T_{3}$. Estas quantidades seriam redistribuídas a um número pequeno de agregados, de acordo com as pontuações e caraterísticas destes, e o problema de distribuição de recursos a ações seria novamente resolvido para estes agregados. O procedimento de redistribuição de recursos sobrantes seria repetido até que as sobras fossem suficientemente pequenas para não permitir a seleção de mais ações.

\section{Impacto para a empresa}

A abordagem apresentada permite apoiar a obtenção de decisões solidamente fundamentadas. A existência de uma estrutura de preferências explícita permite compreender (e justificar) melhor as decisões tomadas, além de permitir também detetar com mais facilidade incoerências no processo de decisão. Esta abordagem permite, pois, uma maior responsabilização dos decisores, ajudando-os a perceber melhor onde poderão ter ocorrido erros de avaliação quando se constate que as decisões tomadas não foram as mais adequadas. O facto desta abordagem de avaliação necessitar da intervenção de vários agentes de decisão, correspondentes a vários níveis de gestão da empresa, leva a que esses agentes de decisão (que vão desde a gestão de topo aos responsáveis pelos agregados/projetos) pensem, discutam e explicitem os seus pressupostos. Além disso, perante os resultados e processo de avaliação, os decisores podem alterar a opinião ou a estrutura de prioridades. As estruturas hierárquicas apresentadas levam a que agentes de decisão de um determinado nível da hierarquia não possam intervir diretamente nas decisões de outros níveis. Esta diferenciação conduz, assim, a resultados que consideram variados pontos de vista e objetivos por parte da empresa.

Através do conceito de agregado, a abordagem permite também a harmonização de decisões sobre ações inter-relacionadas que estão situadas em clusters diferentes. 
O modelo de avaliação proposto permite ainda apoiar decisões intercalares (entre dois momentos de planeamento e decisão) quando surgem situações imprevistas, como o aparecimento de novas oportunidades não previstas no momento do planeamento. Numa situação como esta, tais oportunidades podem ser integradas facilmente no modelo, e no caso de se decidir aproveitar tais oportunidades, a realocação dos recursos também pode ser feita com base no modelo.

Esta abordagem também ajuda a incentivar a identificação de oportunidades estratégicas e de flexibilidade operacional nas ações e agregados da empresa, através da definição dos critérios (subcritérios). Estas oportunidades estratégicas e de flexibilidade operacional passam a ser um fator relevante nas decisões a tomar, levando os responsáveis pelas propostas a procurá-las ativamente.

A solução foi aplicada na empresa a um conjunto de agregados e ações de teste, a partir de um protótipo desenvolvido em Microsoft Excel. Para tal, foi determinada a estrutura de preferências, com auxílio de elementos ligados à gestão da empresa, e esta foi utilizada para fazer um conjunto de avaliações. Os resultados assim obtidos foram analisados por elementos da empresa, por forma a verificar se estavam de acordo com as expectativas de atratividade das ações e agregados considerados. Esta análise permitiu fazer uma primeira calibração do modelo, após a qual se considerou que os resultados estavam em consonância com as expectativas.

Após esta primeira validação, passou-se à fase de construção da aplicação a ser usada pela empresa, e da sua integração nos sistemas da empresa. Esta integração permitiu que a solução desenvolvida pudesse passar a ser usada requerendo um esforço muito menor de introdução de dados. Mais uma vez, os testes efetuados a um conjunto de ações e agregados, com base na estrutura de preferências eliciada a elementos ligados à gestão da empresa, mostraram que a solução contribui para tornar claro e objetivo o processo de alocação de recursos, conduzindo a uma utilização mais eficientes dos recursos.

\section{Conclusões}

A abordagem de avaliação apresentada permite avaliar os projetos de Inovação, Investigação e Desenvolvimento de uma empresa de 
telecomunicações: a PT Inovação. Esta avaliação é feita em dois níveis distintos de decisão: a ação e o agregado de ações. Enquanto a ação é um conceito já utilizado na empresa, o agregado é um novo conceito introduzido e que corresponde a um conjunto de ações inter-relacionadas vocacionadas para um mesmo serviço ou produto. Em cada um dos níveis de decisão, são utilizados diferentes critérios, estruturados de forma hierárquica. São considerados diferentes tipos de ações e de agregados e o modelo prevê uma diferenciação dos pesos dos critérios consoante o tipo de ação ou agregado em avaliação. O modelo de avaliação apresentado permite considerar critérios, quer qualitativos, quer quantitativos (como sendo o caso de alguns critérios financeiros). Para além deste facto, o modelo permite também lidar com um grande número de alternativas. Esta abordagem não necessita que o decisor ou responsável de projeto ou ação proceda a todas as comparações entre as alternativas apresentadas, mas antes permite que sejam feitas apenas um número mínimo de comparações, evitando demasiado esforço e informação requerida ao decisor.

O modelo de avaliação destina-se, principalmente, a apoiar os decisores na tomada de decisões sobre alocação de pessoas a projetos. O modelo tem um papel importante na deteção de incoerências no processo de avaliação, integração de decisões intercalares neste processo, e identificação de fontes de erros de avaliação. A hierarquização do modelo permite também a identificação da estrutura de preferências dos diferentes órgãos de decisão que participam no processo de avaliação.

Este modelo de avaliação pode também ajudar a incentivar na identificação de oportunidades estratégicas e de flexibilidade operacional nos projetos da empresa.

\section{Bibiografia}

CARLSSON, C. e Outros, A fuzzy approach to RED project portfolio selection. International Journal of Approximate Reasoning, 44: p. 93-105, 2007.

DYER, J.S., A clarification of "remarks on the analytic bierarchy process. Management Science, 36(3): p. 274-275, 1990a.

DYER, J.S., Remarks on the analytic bierarchy process. Management Science, 36(3): p. 249-258, 1990b. 
FARRUKH, C. e Outros, Developing a process for the relative valuation of R\&D programmes. R\&D Management. 30(1): p. 43-53, 2000.

GODINHO, P. e Outros, Some issues about the application of the analytic hierarchy process to RED project selection. Global Business and Economics Review, 13(1): p. 26-41, 2011.

HARKER, P.T., Incomplete pairwise comparisons in the analytic hierarchy process. Mathematical Modelling, 9(11): p. 837-848, 1987.

HARKER, P. e L. Vargas, The theory of ratio scale estimation: Saaty's analytic hierarchy process. Management Science, 33: p. 1383-1403, 1987.

HARKER, P. e L. Vargas, Reply to 'Remarks on analytic bierarchy process'. Management Science, 36: p. 269-273, 1990.

HOLDER, R., Some comment on the analytic bierarchy process. Journal of the Operational Research Society, 41: p. 1073-1076, 1990.

HOLDER, R., Response to holder's comments on the analytic hierarchy process: Response to the response. Journal of the Operational Research Society, 42: p. 914-918, 1991.

ISHIZAKA, A. e A. Labib, Review of the main developments in the analytic hierarchy process. Expert Systems with Applications, 38: p. 14336-14345, 2011.

KABLAN, M.M., Decision support for energy conservation promotion: an analytic bierarchy process approach. Energy Policy, 32(10): p. 1151-1158, 2004.

POH, K., B.W. Ang, e F. Bai, A comparative analysis of RED project evaluation methods. R\&D Management. 31(1): p. 63-75, 2001.

SAATY, T.L., The Analytic Hierarchy Process: Planning, Priority, Setting Resource Allocation, New York: McGraw-Hill, 1980.

SAATY, T.L., Axiomatic foundation of the analytic bierarchy process. Management Science, 32: p. 841-855, 1986.

SAATY, T.L., An exposition of the AHP in reply to the paper: 'Remarks on the analytic bierarchy process'. Management Science, 36: p. 259-268, 1990.

SAATY, T.L., Response to bolder's comments on the analytic bierarchy process. Journal of the Operational Research Society, 42: p. 909-929, 1991.

SAATY, T.L., Highlights and critical points in the theory and applications of the analytic bierarchy process. European Journal of Operational Research, 74: p. 426-477, $1994 \mathrm{a}$.

SAATY, T.L., Fundamentals of Decision Making and Priority Theory with the Analytic Hierarchy Process, RWS Publications, 1994b.SAATY, T.L., That is not the analytic hierarchy process: what the AHP is and what it is not. Journal of Multi-Criteria Decision Analysis, 6(6): p. 324-335, 1997.

SAATY, T.L., Rank from comparisons and from ratings in the analytic bierarchy/network processes. European Journal of Operational Research, 168: p. 557-570, 2006.

SHIN, C.-O., S.-H. Yoo, e S.-J. Kwak, Applying the analytic bierarchy process to evaluation of the national nuclear RED projects: The case of Korea. Progress in Nuclear Energy, 49(5): p. 375-384, 2007.

STAM, A. e P. Duarte Silva, On multiplicative priority rating methods for AHP. European Journal of Operational Research, 145: p. 92-108, 2003. 